$\begin{array}{r}\text { DARMABAKTI CENDEKIA: } \\ \text { Journal of Community Service and Engagements } \\ \text { www.e-journal.unair.ac.id/index.php/DC } \\ \hline\end{array}$

\section{INTEGRATED MARKETING COMMUNICATION STRATEGY FOR SME (SMALL AND MEDIUM ENTERPRISES) OF TRADITIONAL HERBAL AND BEVERAGES}

\author{
STRATEGI KOMUNIKASI PEMASARAN TERPADU UNTUK PELAKU \\ UMKM (USAHA MIKRO, KECIL, DAN MENENGAH) JAMU DAN \\ MINUMAN TRADISIONAL
}

Scope:

Social-economic

\author{
Rani Sukma Ayu Suteja*, Liestianingsih Dwi Dayanti, Angga Prawadika Aj@ Santi Isnaini, \\ Yayan Sakti Suryandaru, Titik Puji Rahayu Andria Saptyasar@, Irfan Wahyud@ Ratih Puspa, \\ Nurul Ratna Sar国, Dina Septiani回, Nisa Kurnia Illahiati \\ Department of Communication, Faculty of Social Science and Political Science, Universitas Airlangga, Surabaya-Indonesia
}

\begin{abstract}
$A B S T R A C T$
Background: This program begins with observation on SME of traditional herbal and beverages in Kampung Genteng Candirejo Surabaya. Early observation shows difficulties faced by SME to market their products. Objective: This program is expected to provide information and education about marketing communication strategies for SME of traditional herbal and beverages in Kampung Herbal Candirejo Surabaya. Method: Early observation is to find problems, conducting seminar and workshop, and also evaluating community empowerment. Results: Audiences understand about the impotances of marketing communication and innovation. They also improve their skills in using integrated marketing communication to sell their products to customers. Conclusion: This community service program has achieved its goals.
\end{abstract}

\author{
ARTICLE INFO \\ Received 15 August 2020 \\ Revised 15 September 2021 \\ Accepted 19 October 2021 \\ Online 10 November 2021 \\ *Correspondence (Korespondensi): \\ Rani Sukma Ayu Suteja \\ E-mail: \\ ranisukma@fisip.unair.ac.id \\ Keywords: \\ Communication; Marketing, \\ SME; Herbal medicine
}

Kata kunci:

Komunikasi, pemasaran,

UMKM, jamu 


\section{PENDAHULUAN}

Kampung Genteng Candirejo atau dikenal juga dengan nama Kampung Herbal Genteng Candirejo, berlokasi di RT II RW 8 Kelurahan dan Kecamatan Genteng, Kota Surabaya. Kampung ini merintis pengelolaan lingkungan hidup sejak tahun 2006 dan aktif pada tahun 2007. Kampung Genteng Candirejo ini merupakan sentra olahan herbal yaitu makanan dan minuman tradisional. Masing-masing keluarga di kampung ini memproduksi olahan herbal terutama untuk minuman tradisional. Diantaranya adalah sinom, temulawak, kunyit asam, rosella, teh rempah, sari belimbing wuluh, sari apel, dan beras kencur. Pelaku usaha utama di Kampung Genteng Candirejo adalah ibu-ibu (Nur and Siringoringo, 2019), Selain itu, tujuan dari para tbu dart Kampung Herbal Genteng Candirejo juga untuk melestarikan jamu dan minuman tradisional Indonesia sebagai salah satu produk budaya, tradisi, dan warisan Indonesia.

Akan tetapi, menurut penelitian yang dilakukan oleh Kementerian Pedagangan Republik Indonesia pada tahun 2009, pelaku Usaha Mikro, Kecil, dan Menengah (UMKM) jamu saat ini menghadapi banyak tantangan dalam melestarikan produk jamu. Pertama dari sisi kebijakan pemerintah, kurangnya pembinaan pemerintah terhadap pelaku usaha jamu yang berasal dari kalangan pelaku UMKM, peraturan yang menghambat, kesulitan pengemasan produk dan pemberian merek, kesulitan dalam memperoleh bahan baku, serta persaingan dengan perusahaan farmasi dan beredarnya jamu kimia. Kedua, dari sisi konsumennya, akibat adanya arus globalisasi dan pertukaran budaya luar yang begitu besar, jamu dipersepsi sebagai produk tradisional konsumsi orang kampung dan ketinggalan zaman. Masyarakat Indonesia sendiri saat ini sudah beralih pada obat farmasi yang dianggap lebih praktis. Semakin modern, pengetahuan masyarakat tentang khasiat dan mutu jamu juga sudah berkurang. Ketidakjelasan label, kualitas, dan informasi pada produk jamu pun meningkatkan ketidaknyamanan konsumen saat mengonsumsi jamu. Belum lagi jamu dianggap memiliki bentuk dan rasa yang dinilai pahit serta tidak sedap Kemendag.go.id, 2014). Hal-hal ini pulalah yang juga dihadapi oleh pelaku usaha jamu dan minuman tradisional di Kampung Herbal Genteng Candirejo.

Oleh karena itu, pelaku usaha produksi jamu yang ingin tetap eksis di era globalisasi, dituntut untuk dapat selalu kreatif dan terus berinovasi dalam pengembangan produk untuk dapat mengikuti selera pasar modern (Fatonah, 2017), Pentingnya jamu untuk bertahan juga disadartoleh Kementerian Koordinator bidang Perekonomian dengan meluncurkan program "Jamu Brand Indonesia" pada tahun 2006 untuk mendukung pengembangan industri jamu (Kemenko Perekonomian, 2011) Selain berinovasi, agar jamu terus-menterus dapat dikenal dan dilestarikan oleh masyarakat Indonesia, pelaku usaha produksi jamu juga harus memiliki strategi komunikasi yang tepat untuk memasarkan dan memromosikan produknya. Dalam rangka mengembangkan usaha, pelaku usaha harus terus berinovasi dan berkreasi, kemudian secara terus-menerus memperkenalkan, menginformasikan, serta mempersuasi konsumen agar mau mengonsumsi jamu. Apalagi di era digital saat ini, pelaku usaha produk tradisionalpun harus mampu untuk memadukan berbagai strategi komunikasi untuk mencapai tujuan maksimal dalam memasarkan produknya kepada konsumen atau calon konsumen. Komunikasi pemasaran adalah segala hal yang dilakukan untuk mempengaruhi perilaku atau persepsi konsumen terhadap suatu produk (Callen, 2010). Jntuk memaksimalkan komunikasi pemasaran dikenal istilah komunikasi pemasaran terpadu yaitu penggabungan dari beberapa alat komunikasi pemasaran agar tercapai tujuan pemasaran secara maksimal. Komunikasi pemasaran terpadu terdiri dari penggunaan iklan, direct marketing, public relations, personal selling, sales promotion, dan internet marketing Belch and Belch, 2018).

Berdasarkan hal tersebut, maka Departemen Komunikasi Fakultas IImu Sosial dan Ilmu Politik Universitas Airlangga menyelenggarakan kegiatan pengabdian masyarakat berjudul "Strategi Komunikasi Pemasaran Terpadu untuk Pelaku UMKM Jamu dan Minuman Tradisional". Kegiatan ini bertujuan untuk meningkatkan pemahaman pelaku UMKM jamu dan minuman tradisional tentang pentingnya strategi komunikasi pemasaran untuk melestarikan produk jamu. Pengabdian masyarakat ini dilaksanakan di Kampung Herbal Genteng Candirejo, tepatnya di Balai RW 8 Kel/Kec. Genteng, Jalan Genteng Candirejo Surabaya. Kampung Herbal Candirejo dinilai memiliki potensi karena pelaku UMKM di sana masih memiliki semangat yang tinggi dalam melestarikan produk tradisional sehingga kegiatan pengabdian masyarakat akan semakin memaksimalkan potensi. Selain itu, kampung ini merupakan salah satu kampung wisata atau kampung percontohan, sehingga diharapkan pelaku UMKM di sana dapat menyebarkan informasi dan edukasi yang didapatkan dari kegiatan pengabdian masyarakat. Adapun kegiatan pengabdian masyarakat ini bekerjasama pula dengan perusahaan, asosiasi, atau komunitas yang berkaitan dengan jamu tradisional yaitu PT. 
Jamu IBOE Jaya dan Fakultas Farmasi Universitas Airlangga. Program pengabdian masyarakat ini melibatkan hampir seluruh dosen di Departemen Komunikasi FISIP Universitas Airlangga serta memperoleh bantuan khusus dari pakar jamu dan pengobatan herbal dari Fakultas Farmasi Universitas Airlangga.

\section{METODE}

Pelaksanaan kegiatan pengabdian masyarakat ini dilaksanakan dengan beberapa tahap yaitu tahap persiapan, tahap pelaksanaan, dan tahap monitoring-evaluasi. Tahap 1 merupakan tahap persiapan. Persiapan kegiatan pengabdian masyarakat dilaksanakan mulai dari bulan MaretJuli 2019 dengan agenda sebagai berikut: (1) Memetakan permasalahan mitra; (2) Rapat bersama mitra dan menentukan pelaksanaan; (3) Mengurus perijinan di lokasi sasaran pengabdian masyarakat; (4) Mengunjungi kelompok sasaran yaitu pelakuUMKM jamu tradisional;(5)Melakukan pra-survey ke lokasi untuk memperkenalkan kegiatan termasuk maksud dan tujuan; dan (6) Melakukan perjanjian kerjasama dengan PT. Jamu Iboe Jaya dan Fakultas Farmasi sebagai pembicara tamu dalam kegiatan pengabdian masyarakat.

Selanjutnya tahap 2 yaitu pelaksanaan kegiatan. Kegiatan pengabdian masyarakat ini dilaksanakan dengan agenda sebagai berikut: (1) Memberikan pemahaman kepada pelaku UMKM jamu dan minuman tradisional mengenai pentingnya higienitas produk dan bahan jamu; (2) Memberikan pemahaman kepada pelaku UMKM jamu dan minuman tradisional tentang potensi industri jamu; (3) Membantu pelaku UMKM jamu tradisional dan masyarakat setempat dalam memahami pentingnya inovasi dan strategi komunikasi pemasaran terpadu dalam kemajuan usaha; dan (4) Mengajarkan keahlian (skills) yang diperlukan untuk memahami dan menentukan strategi komunikasi pemasaran terpadu.

Selanjutnya, tahap akhir yaitu tahap monitoring dan evaluasi. Monitoring dan evaluasi dengan meninjau hal-hal sebagai berikut: (1) Meningkatnya pemahaman mengenai pentingnya strategi komunikasi dan inovasi di era global; (2) Meningkatnya keahlian pelaku UMKM jamu tradisional dan masyarakat setempat dalam menentukan dan memaksimalkan strategi komunikasi pemasaran terpadu untuk kemajuan usaha jamu;(3) Meningkatnya pengetahuan pelaku UMKM jamu tradisional dan masyarakat setempat mengenai kelebihan komunikasi pemasaran terpadu. Kemudian setelah keseluruhan kegiatan telah dilaksanakan yang perlu dilakukan (1) Penulisan laporan kegiatan pengabdian pada masyarakat; (2) Penyusunan laporan keuangan dan laporan pertanggungjawaban; dan (3) Merencanakan keberlanjutan kegiatan pengabdian masyarakat.

\section{HASIL DAN PEMBAHASAN}

Berdasarkan latar belakang masalah dan metode yang dipaparkan, beberapa permasalahan dari mitra adalah (1) Adanya arus globalisasi dan pertukaran budaya yang begitu besar, produk tradisional seperti jamu perlahan-lahan mulai ditinggalkan oleh konsumen, akibatnya pelaku UMKM jamu tradisional kehilangan konsumennya karena tidak bisa mengikuti perkembangan zaman; (2) Kurangnya kesadaran dan pengetahuan mengenai strategi komunikasi pemasaran terpadu di kalangan pelaku UMKM jamu tradisional sehingga kesulitan mengenalkan produk jamunya ke khalayak luas; (3) Kurangnya kesadaran mengenai pentingnya sebuah merek agar produk dapat dipasarkan dan dipromosikan secara layak. Oleh karena itu, kegiatan pengabdian masyarakat yang dilaksanakan adalah berupa seminar dan workshop dengan tema "Strategi Komunikasi Pemasaran Terpadu untuk UMKM Jamu dan Minuman Tradisional", pada hari Sabtu, 27 Juli 2019, di Balai RW 8 Kel/Kec, Genteng, Jalan Genteng Candirejo, Surabaya. Lokasi ini biasa dikenal dengan Kampung Herbal Genteng Candirejo.

Kegiatan pengabdian masyarakat dihadiri oleh tim dari Departemen Komunikasi FISIP Universitas Airlangga, salah satu dosen dari Fakultas Farmasi Universitas Airlangga, dan salah satu pejabat dari PT. Jamu IBOE Jaya. Kegiatan pengabdian masyarakat ini juga dihadiri sebanyak kurang lebih 35 (tiga puluh lima) peserta yang terdiri dari ibuibu pelaku UMKM jamu dan minuman tradisional di kampung Herbal Genteng Candirejo. Secara rinci, kegiatan pengabdian masyarakat ini dilaksanakan dengan susunan sebagai berikut:

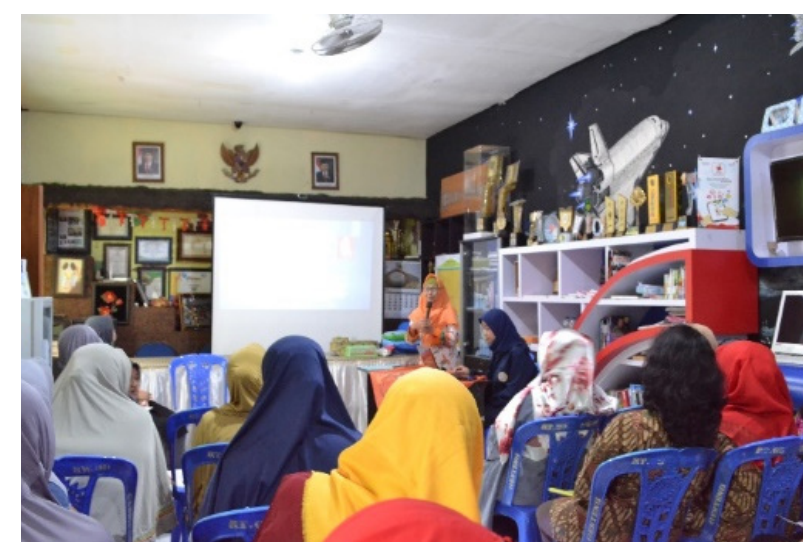

Gambar 1. Peserta Kegiatan 
Tabel 1. Susunan Acara Kegiatan Pengabdian Masyarakat

\begin{tabular}{|c|c|c|}
\hline Waktu & Kegiatan & Pengisi Acara \\
\hline $08.00-08.30$ & Registrasi & Mahasiswa \\
\hline $08.30-08.45$ & $\begin{array}{l}\text { Pembukaan: } \\
\text { - Sambutan dari Departemen Komunikasi } \\
\text { - Sambutan dari Ketua RT }\end{array}$ & $\begin{array}{l}\text { Ibu Dr. Liestianingsih, M.Si. } \\
\text { Bapak Syahri (Ketua RT) } \\
\text { MC: Mahasiswa }\end{array}$ \\
\hline $08.45-09.30$ & $\begin{array}{l}\text { Higienitas produk dan bahan jamu dan minuman } \\
\text { tradisional }\end{array}$ & $\begin{array}{l}\text { Fakultas Farmasi UNAIR } \\
\text { Moderator: Bapak Irfan Wahyudi, Ph.D }\end{array}$ \\
\hline $09.30-10.00$ & $\begin{array}{l}\text { Pengembangan industri jamu dan minuman } \\
\text { tradisional }\end{array}$ & $\begin{array}{l}\text { Bapak Perry Angglishartono dari } \\
\text { PT. Jamu IBOE Jaya } \\
\text { Moderator: Ibu Titik Puji Rahayu, Ph.D }\end{array}$ \\
\hline $10.00-11.00$ & $\begin{array}{l}\text { Menjual jamu dan minuman tradisional melalui } \\
\text { media sosial }\end{array}$ & $\begin{array}{l}\text { Ibu Dina Septiani, Ph.D } \\
\text { Moderator: Ibu Dr. Andria Saptyasari }\end{array}$ \\
\hline $11.00-12.00$ & $\begin{array}{l}\text { Meningkatkan nilai jual jamu dan minuman } \\
\text { tradisional }\end{array}$ & $\begin{array}{l}\text { Ibu Nurul Ratna Sari, M.Comm } \\
\text { Ibu Dr. Santi Isnaini } \\
\text { Moderator: Bapak Angga Prawadika Aji, MA. }\end{array}$ \\
\hline $12.00-12.30$ & Diskusi dengan peserta & Tim \\
\hline $12.30-13.00$ & Ramah tamah dan penutupan & Tim \\
\hline
\end{tabular}

Setelah dibuka oleh ketua tim pengabdian masyarakat yang juga selaku Kepala Departemen Komunikasi FISIP Universitas Airlangga dan ketua RT dari Kampung Genteng Candirejo, acara langsung dilanjutkan dengan paparan dari pemateri pertama yaitu Ibu Dra. Rakhmawati, M.Si, Apt dari Fakultas Farmasi Universitas Airlangga dengan materi "Higienitas Produk dan Bahan Jamu dan Minuman Tradisional". Dalam paparannya, Ibu Dra. Rakhmawati, M.Si, Apt menyampaikan bahwa tujuan dasar mengonsumsi jamu adalah supaya tubuh menjadi sehat, bugar, dan panjang umur. Oleh karena itu, supaya dapat mencapai tujuan yang maksimal, maka pemilihan bahan dasar yang tepat, berkhasiat, dan higienis menjadi sangat penting. Menurut paparan beliau, hal ini sejalan dengan tujuan pemerintah yang disampaikan melalui Badan Pengawas Obat dan Makanan Republik Indonesia (BPOM RI). BPOM RI mengeluarkan Peraturan Kepala Badan Pengawas Obat dan Makanan Republik Indonesia nomor hk.03.1.23.06.11.5629 tahun 2011 tentang "Persyaratan Teknis Cara Pembuatan Obat Tradisional Yang Baik". Dalam peraturan ini diuraikan pentingnya penjaminan mutu melalui pengaturan personalia, bangunan, sanitasi, dokumentasi, produksi, pengawasan mutu, penyimpanan, pengiriman, dan inspeksi. Kesimpulan dari paparan Ibu Dra. Rakhmawati, M.Si adalah bahwa sebagai pelaku UMKM jamu dan minumal tradisional harus menjaga kebersihan diri penjual, bahan baku yang benar dan bersih, kebersihan peralatan dan tempat meracik, cara pembuatan dan pengolahan yang baik, cara penyimpanan dan wadah yang benar, serta cara penyajian yang baik, sehingga khasiat dari jamu bisa maksimal.

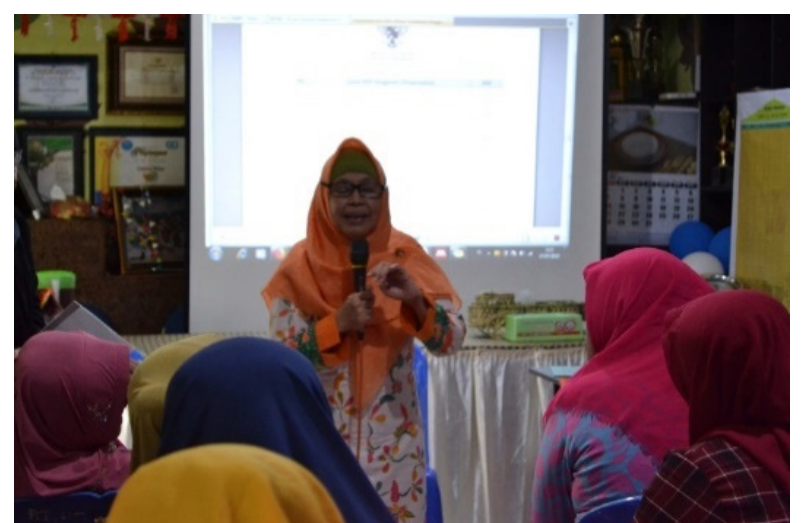

Gambar 2. Seminar dan Workshop dari perwakilan Fakultas Farmasi UNAIR

Pemateri yang kedua adalah Bapak Perry Angglishartono selaku product group manager dari PT. Jamu IBOE Jaya dengan materi "Pengembangan Industri Jamu dan Minuman Tradisional”. Dalam paparannya, beliau menyampaikan potensi industri jamu di Indonesia dan dunia, apalagi saat ini jamu mendapat dukungan penuh dari pemerintah Indonesia. Selain itu, tantangan industri jamu juga menjadi poin paparan Bapak Perry Angglishartono. Saat ini, industri jamu menghadapi 4 (empat) tantangan yang terdiri dari: (1) Persepsi: persepsi yaitu adanya anggapan dari generasi muda bahwa jamu merupakan konsumsi orang tua dan sangat ketinggalan zaman. (2) Regenerasi: tantangan berikutnya adalah regenerasi karena tidak banyak 
orang yang mau melanjutkan usaha jamu karena beranggapan jamu tidak potensial. (3) Sosialisasi: Sosialisasi tentang khasiat dan pentingnya mengonsumsi jamu, telah kalah dengan obat-obat pabrikan dan kimia, sehingga jamu semakin tidak dikenal. (4) Regulasi: Regulasi pemerintah yang menyulitkan pelaku UMKM jamu dan minuman tradisional, padahal para pelaku UMKM ini adalah kunci dalam merubah persepsi tentang jamu, melakukan regenerasi, dan menggencarkan sosialisasi. Oleh karena itu, penting agar pelaku UMKM dapat meneruskan usahanya, membangun merek dagang, dan mengurus izin dari Badan Pengawas Obat dan Makanan Republik Indonesia (BPOM RI), agar usahanya dapat bertahan dan dapat dikenal oleh masyarakat.

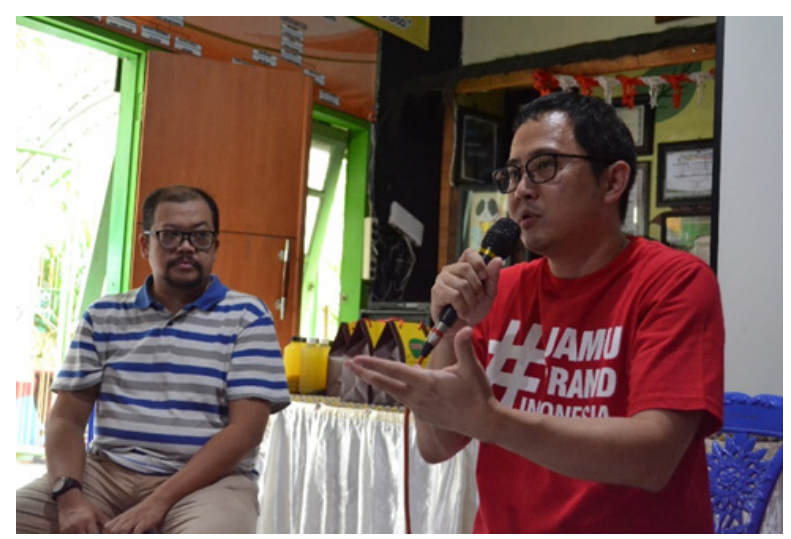

Gambar 3. Seminar dan Workshop dari PT. Jamu IBOE Jaya

Pemateri keempat dan ketiga berasal dari Departemen Komunikasi FISIP Universitas Airlangga dengan tema "Menjual Jamu dan Minuman Tradisional melalui Media Sosial" dan "Meningkatkan Nilai Jual Jamu dan Minuman Tradisional". Pada sesi ini, para pelaku UMKM diberi materi tentang strategi komunikasi pemasaran terpadu dasar dan diperkenalkan berbagai macam sosial media serta aplikasi yang dapat digunakan untuk memromosikan produk jamu, diantaranya adalah Facebook, Instagram, Shopee, Go-food, dan Grab-food. Dalam kesempatan tersebut, pelaku UMKM juga diajarkan dan praktek langsung membuat akun sosial media dan aplikasi. Paparan juga termasuk kelebihan dan kekurangan masingmasing sosial media dan aplikasi. Selanjutnya, materi yang disampaikan juga termasuk pentingnya pemberian label dan kemasan yang unik dan menarik sehingga produk dapat diminati oleh masyarakat luas.

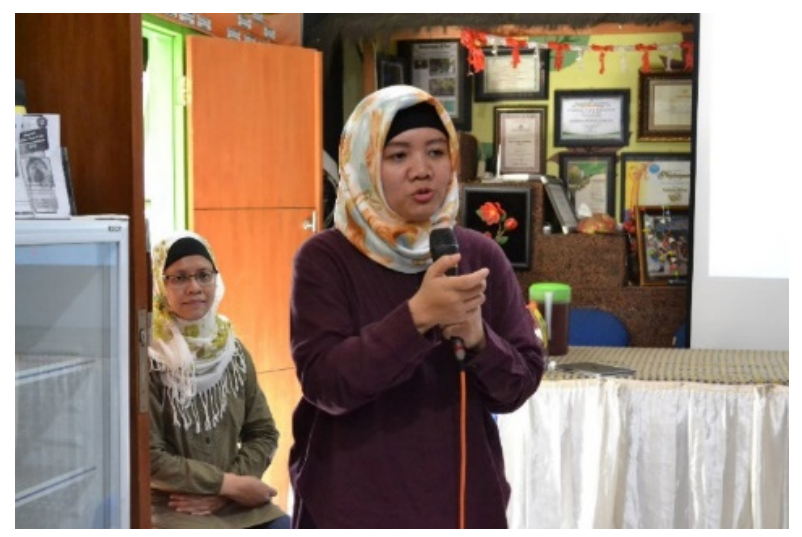

Gambar 4. Seminar dan Workshop dari Departemen Komunikasi FISIP UNAIR

\section{KESIMPULAN DAN SARAN}

Setelah diadakan seminar dan workshop, para peserta mendapatkan pemahamanan mengenai pentingnya strategi komunikasi dan inovasi di era global, mengasah keahlian dalam menentukan dan memaksimalkan strategi komunikasi pemasaran terpadu untuk kemajuan usaha jamu, serta mendapat pengetahuan mengenai kelebihan komunikasi pemasaran terpadu. Selain itu, peserta juga mendapat pemahaman tentang pentingnya menjaga higienitas produk Saran yang dapat diberikan adalah: (1) Pelaku UMKM jamu dan minuman tradisional memiliki peran kunci dalam melestarikan jamu di Indonesia, sehingga pemerintah diharapkan dapat pro-aktif dalam memberikan fasilitas; dan (2) Pengabdian masyarakat dengan tema yang sama perlu dilaksanakan di sentra-sentra jamu tradisional lainnya agar pengetahuan tentang komunikasi pemasaran jamu meningkat dan promosi jamu dapat berjalan maksimal.

\section{UCAPAN TERIMA KASIH}

Penulis mengucapkan terima kasih kepada Universitas Airlangga sebagai pemberi dana sehingga kegiatan pengabdian masyarakat ini dapat direalisasi. Penulis juga mengucapkan terima kasih kepada para warga Kampung Genteng Candirejo, PT. Jamu IBOE JAYA, dan Fakultas Farmasi Universitas Airlangga yang telah bersedia berpartisipasi serta bekerjasama dalam kegiatan. Dengan ini, penulis menyatakan tidak ada konflik kepentingan dengan pihak-pihak yang terkait dalam kegiatan pengabdian masyarakat ini. 


\section{DAFTAR PUSTAKA}

Belch, G.E., Belch, M.A., 2018. Advertising and Promotion: an integrated marketing communications perspective., 11th ed. McGraw-Hill Education, Boston.

Callen, B., 2010. Manager's Guide to Marketing, Advertising, and Publicity. McGraw-Hill Education, Boston.

Fatonah, T., 2017. 3 Penyebab Besar Bangkrutnya Pabrik Jamu Legendaris Nyonya Meneer [WWW Document]. URL http://wow. tribunnews.com/2017/08/05/3-penyebabbesar-bangkrutnya-pabrik-jamu-legendarisnyonya-meneer?page=all (diakses 9.3.19).
Kemendag.go.id, 2014. Kajian Jamu [WWW Document]. URL https://www.kemendag. go.id/files/pdf/2014/01/06/Kajian-Jamu.pdf. (diakses 9.3.19).

Kemenko Perekonomian, 2011. 6 Tahun Brand Jamu Indonesia [WWW Document]. URL https://ekon.go.id/publikasi/detail/1620/6tahun-brand-jamu-indonesia (diakses 9.3.19).

Nur, M., Siringoringo, J.D., 2019. Kampung "Segudang Prestasi" Genteng Candirejo Surabaya [WWW Document]. URL https:// tunashijau.id/2019/07/kampung-segudangprestasi-genteng-candirejo-surabaya/ (diakses 9.3.19). 